\title{
Journal of Applied Structural Equation Modeling
}

eISSN: $2590-4221$

Journal of Applied Structural Equation Modeling: 5(1),i-xiv, 2021

DOI: $10.47263 / J A S E M .5(1) 06$

\section{PLS-SEM STATISTICAL PROGRAMS: A REVIEW}

\author{
Mumtaz Ali Memona*, T. Ramayah ${ }^{\mathrm{b}}$, Jun-Hwa Cheah ${ }^{\mathrm{c}}$, \\ Hiram Ting ${ }^{\mathrm{d}}$, Francis Chuah ${ }^{\mathrm{e}}$ and Tat Huei Cham ${ }^{\mathrm{f}}$ \\ ${ }^{a}$ NUST Business School, National University of Sciences and Technology (NUST), Islamabad, Pakistan \\ ${ }^{\mathrm{b}}$ School of Management, Universiti Sains Malaysia, Penang, Malaysia \\ 'School of Business and Economics, Universiti Putra Malaysia, Selangor, Malaysia \\ ${ }^{\mathrm{d}}$ Faculty of Hospitality and Tourism Management, UCSI University, Sarawak, Malaysia \\ 'Othman Yeop Abdullah Graduate School of Business, Universiti Utara Malaysia, Kedah, Malaysia \\ ${ }_{\mathrm{f}}^{\mathrm{F}}$ aculty of Accountancy and Management, Universiti Tunku Abdul Rahman, Kajang, Malaysia \\ "mumtazutp@gmail.com
}

\begin{abstract}
Partial least squares structural equation modeling (PLS-SEM) is one of the most widely used methods of multivariate data analysis. Although previous research has discussed different aspects of PLS-SEM, little has been done to explain the attributes of the various PLS-SEM statistical applications. The objective of this editorial is to discuss the multiple PLS-SEM applications, including SmartPLS, WarpPLS, and ADANCO. It is written based on information received from the developers via emails as well as our ongoing understanding and experience of using these applications. We hope this editorial will serve as a manual for users to understand the unique characteristics of each PLS-SEM application and make informed decisions on the most appropriate application for their research.
\end{abstract}

Keywords: SmartPLS, ADANCO, WarpPLS, PLS-SEM, PLS Path Modeling

\section{INTRODUCTION}

Partial least squares structural equation modeling (PLS-SEM), also known as PLS Path Modeling, is one of the most widely used methods of multivariate data analysis among business and social science scholars. Primarily used to examine models with latent variables, PLS-SEM has been a popular choice among researchers and students since the early 2000 s following its rapid development. A simple Google Scholar search (Term = "PLS-SEM") retrieves more than 300,000 documents that discuss PLS-SEM either directly or indirectly. Most importantly, papers using PLS-SEM methods have been published in top ranked journals with high impact factors; this number is increasing day by day. One of the reasons behind PLS-SEM's wide acceptance is its easy-to-use visual interface, which enables researchers to simultaneously analyze relationships between observed and latent variables in a complex model and perform multiple robustness assessments (i.e., endogeneity test) while considering the measurement error inherent in the evaluation of abstract concepts (Hair \& Sarstedt, 2019; Sarstedt et al., 2016). Therefore, researchers from various business and social science disciplines, including human resource 
management, marketing, tourism, hospitality, family business, accounting and finance, education, supply chain, entrepreneurship, organizational psychology, higher education, information systems, psychology, sociology, and nursing, use PLS-SEM for data analysis in their studies. Even software engineering researchers have started using PLS-SEM in their research (Russo \& Stol, 2021).

After our earlier works on data analysis and methodological issues (Memon et al., 2017; Memon et al., 2018; Memon et al., 2019; Memon et al., 2020), as well as our latest work on multigroup analysis using PLS-SEM (Cheah et al., 2020b), we revisited the most recent queries posted to us. One of the most frequently asked questions has been: Which statistical application (program/software) I should use for my data analysis?" We often try to avoid a direct response to such questions, preferring to suggest articles for reading that we believe can be of help for researchers to better understand and select suitable statistical analysis software. However, this time, we feel somewhat compelled and driven by the necessity to provide a broad review of these applications to appease requests. More importantly, we decided to write something concise to assist researchers, especially students, to make an informed decision on the most appropriate application for their research.

We initially planned to cover both PLS-SEM and covariance-based structural equation modeling (CB-SEM) statistical applications in this editorial. However, we realized that discussing both PLS-SEM and CB-SEM applications in a single editorial might create a sense of comparison between the applications and their respective analytical techniques. Therefore, this editorial focuses on PLS-SEM applications only. We intend to discuss CB-SEM software (AMOS, LISREL, and MPLUS), other PLS-SEM software (XLSTAT, PLS-Graph), generalized structured component analysis (GSCA Pro 1.0), and/or R packages (cSEM and/or SEMinR) in our future editorials.

In this editorial, we discuss three different commercial "stand alone" PLS-SEM applications with graphical user interface, namely SmartPLS (Ringle et al., 2015), WarpPLS (Kock, 2017) and ADANCO (Henseler \& Dijkstra, 2015), which are currently available on the market (see Table 1). These statistical applications are similar in some ways in that they are very user-friendly with their modelling interface and do not require programming knowledge to perform the analyses. We are aware that previous research has mainly looked into explaining the different perspectives of PLS-SEM, such as its analytical method (Hair et al., 2019a), robustness mechanisms (Sarstedt et al., 2020b), usage and reporting mechanisms (Hair et al., 2019a), estimation issues (Cheah et al., 2020a; Sarstedt et al., 2016), achievement of the causal-prediction goal (Chin et al., 2020), matters related to higher-order constructs (Cheah et al., 2019; Sarstedt et al., 2019; Schuberth et al., 2020; Van Riel, 2017), comparison with CB-SEM results (Rigdon et al., 2017), and sample size estimation (Kock \& Hadaya, 2018; Memon et al., 2020). However, little has been done to explain the attributes of the different PLS-SEM statistical applications in a succinct manner. We hope that our work will clarify several queries for SEM users and provide a clear explanation of each PLS-SEM application.

\section{SmartPLS}

SmartPLS is a graphical user interface software for PLS-SEM. The software builds on a modern Java-based programming environment. After the release of the first online version in 2003, SmartPLS 2 was released in 2005, followed by SmartPLS 3 in 2015. The software was developed and has been consistently improved by Christian M. Ringle, Sven Wende, and Jan-Michael Becker. Regular updates and extensions are provided to improve modelling and analysis capabilities. The application is also compatible with current Apple and Microsoft operating systems. 
Table 1: PLS software packages and their functions

\begin{tabular}{|c|c|c|c|}
\hline Attributes & SmartPLS & WarpPLS & ADANCO \\
\hline First Released & 2003 & 2009 & 2014 \\
\hline Current Version & 3.3 .3 & 7.0 & 2.2 .1 \\
\hline Forthcoming Version & 4.0 & NA* & 2.3 \\
\hline Developers & $\begin{array}{l}\text { Christian M. Ringle } \\
\text { Sven Wende } \\
\text { Jan-Michael Becker }\end{array}$ & Ned Kock & Jörg Henseler and team \\
\hline Operating System & Windows and Mac & Windows & Windows and Mac \\
\hline Price (for single user) & $\begin{array}{c}\text { Trial: Free (1 month) } \\
\text { Student: Free (100 samples) } \\
\text { Academic: } 220 \text { EUR/year }\end{array}$ & $\begin{array}{l}\text { Trial: Free (3 months) } \\
\text { US } \$ 127 / \text { year }\end{array}$ & $\begin{array}{c}\text { Trial: US } \$ 3 \text { (1 year) } \\
\text { Students: US } \$ 140 \text { (3 years) } \\
\text { Academic: US } \$ 420 / \text { year }(4 \text { yrs })\end{array}$ \\
\hline $\begin{array}{l}\text { Official Website and } \\
\text { Resources }\end{array}$ & $\underline{\text { https://www.smartpls.com }}$ & $\underline{\text { http://warppls.com }}$ & https://www.composite-modeling.com \\
\hline Contact & support@smartpls.com & support@scriptwarp.com & info@,compositemodeling.com \\
\hline Functions* & $\begin{array}{ll}\text { - } & \text { Basic PLS-SEM Analysis } \\
\text { Partial least squares (PLS) path } \\
\text { modeling }\end{array}$ & 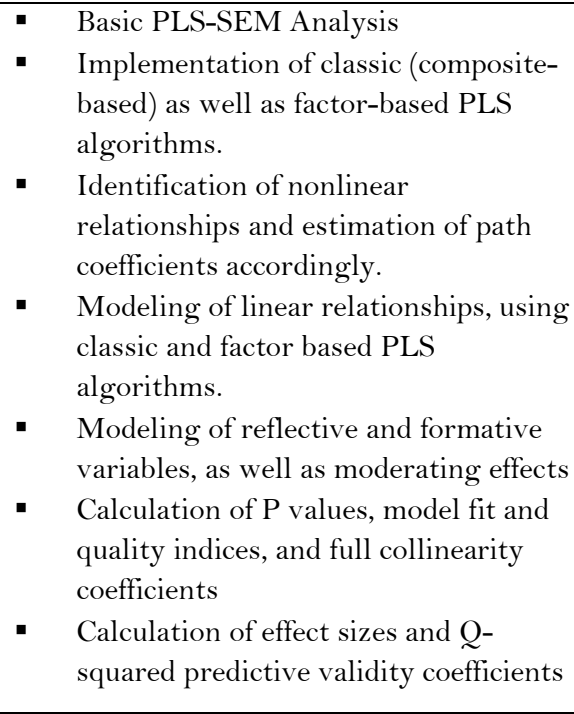 & $\begin{array}{l}\text { - } \text { Basic PLS-SEM Analysis } \\
\text { - } \text { Use of truly reflective measurement } \\
\text { models (latent variables) } \\
\text { - } \text { Use of composite models (emergent } \\
\text { variables) } \\
\text { - } \text { Overall goodness-of-fit tests } \\
\text { - } \text { Assessment of discriminant validity } \\
\text { - } \text { HTMT) } \\
\text { - } \quad \text { Estimation of direct effects } \\
\text { - } \quad \text { Estimation of indirect effects } \\
\text { - } \quad \text { User-defined parameters } \\
\text { - } \quad \text { Advanced bootstrap }\end{array}$ \\
\hline
\end{tabular}




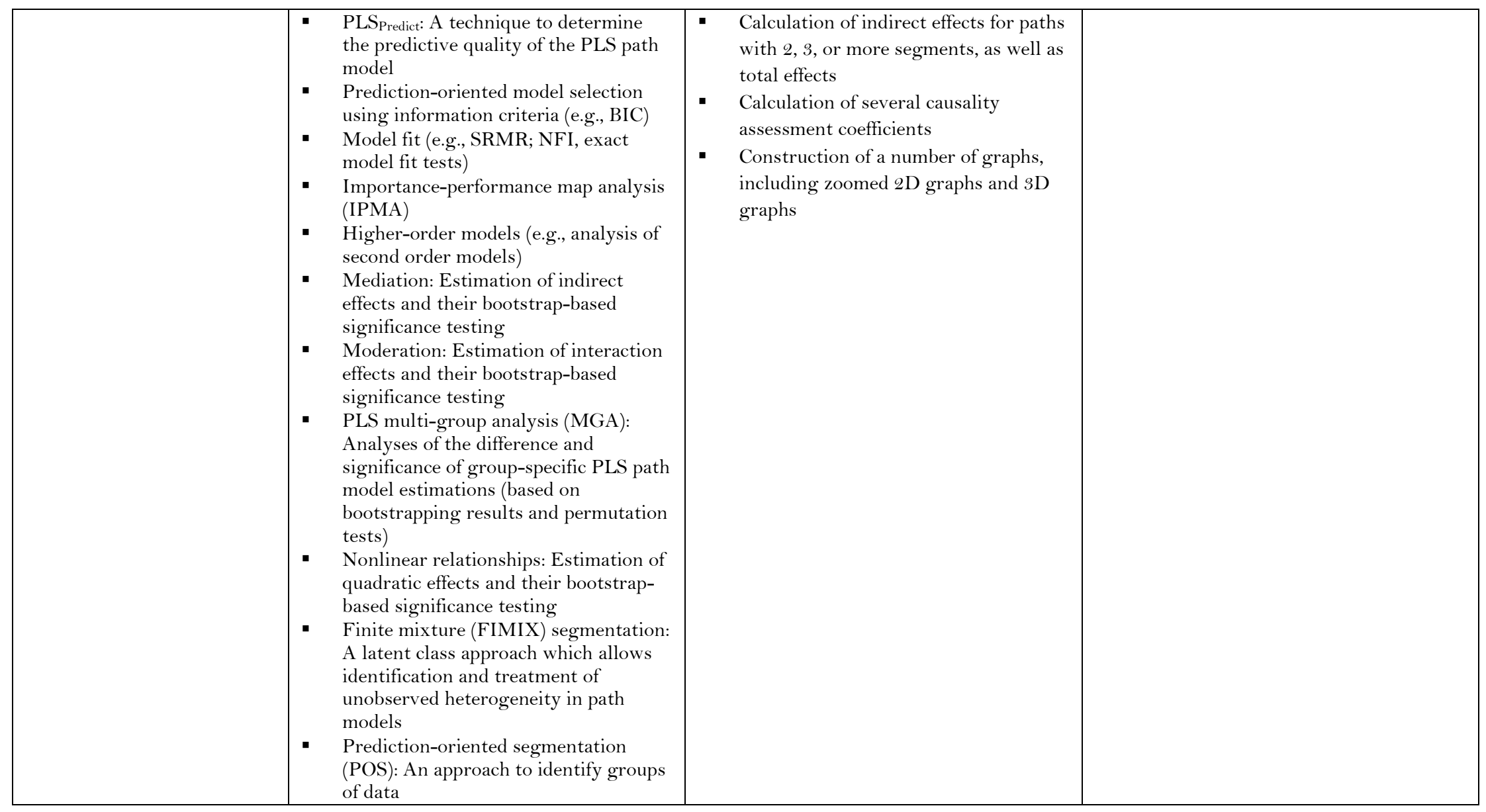

Note: $*$ The functions of all three software were extracted from official software websites 
SmartPLS is a scientifically grounded software. Its philosophy is to implement algorithms and model statistics that have been tested and published in academic journals with peer-reviewed quality assurance. On these grounds, the software aims to provide full transparency on how results are computed, thus ensuring the replicability of findings. At the same time, the software is designed to ensure high usability and user-friendliness to support both beginners and experts in developing scientifically sound and state-of-the-art PLS-SEM analyses (Sarstedt \& Cheah, 2019). According to Google Scholar, more than 10,000 researchers have cited the use of SmartPLS, as required by the license agreement, in their journal publications, including journals ranked or indexed in the Chartered Association of Business Schools (ABS) journals ( 4 and $4 *$ level papers), Australian Business Dean Councils journals (A and A* level papers), and Web of Science (SSCI and SCIE).

In SmartPLS, users can graphically build a PLS path model and estimate it with their data using basic PLS-SEM (Lohmöller, 1989; Wold, 1982), weighted PLS-SEM (Becker \& Ismail, 2016; Cheah et al., 2020a), consistent PLS-SEM (Dijkstra, 2014; Dijkstra \& Henseler, 2015a; 2015b), and sum score regression algorithms (Hair et al., 2022; Marcoulides et al., 2012). The software provides additional algorithms that are useful for understanding and modelling composite-based models, such as advanced bootstrapping (Aguirre-Urreta \& Rönkkö, 2018; Hair et al., 2022), confirmatory tetrad analysis (Gudergan et al., 2008), importance-performance map analysis (Ringle \& Sarstedt, 2016), predictive power assessment using PLSpredict (Shmueli et al., 2016; Shmueli et al., 2019), predictive model comparison based on information criteria such as BIC (Chin et al., 2020; Liengaard et al., 202 1; Sharma et al., 2019a, 2019b), multi-group analysis based on bootstrapping and permutation (Cheah et al., 2020; Chin \& Dibbern, 2010; Hair et al., 2018b), latent class segmentation using finite mixture PLS (Hahn et al., 2002; Sarstedt et al., 2011), and prediction-oriented segmentation (Becker et al., 2013). In addition, it includes state-of-the-art modelling capabilities and model result evaluation, such as discriminant validity assessment using HTMT (Henseler et al., 2015), measurement invariance assessment (MICOM; Henseler et al., 2016), comprehensive descriptive statistics (Hair et al., 2022), goodness of fit criteria (Lohmöller, 1989) and Bollen-Stine bootstrapping-based model fit tests (Dijkstra \& Henseler, 2015a), higherorder models (Cheah et al., 2019; Sarstedt et al., 2019; Wetzels et al., 2009), mediation (Memon et al., 2018; Nitzl et al., 2016), moderation (Becker et al., 2018; Hair et al., 2022; Memon et al., 2019), moderated mediation, and non-linear relationships (Hair, et al., 2018b; Sarstedt et al., 2020a). In addition to the ability to perform explanatory and predictive PLS-SEM research analyses (Hair et al., 2019b; Hair, 2020), SmartPLS fully supports, if desired, conducting a confirmatory composite analysis (Hair et al., 2020; Henseler \& Schuberth 2020; Schuberth et al., 2018).

SmartPLS provides results in well-organized tables and partly in informative results graphics (see Hair et al., 2022; Hair et al., 2018a, Ramayah et al., 2018). Users can also export the results or reports in Excel, HTML, and R formats and save them for later use or sharing with colleagues. In addition, the core results are presented in the graphical modelling window (see Figure 1), which allows easy assessment and exporting of the model.

SmartPLS 4 is currently under development. With its updated technological base, the software promises compatibility with the latest operating systems and trouble-free use in the coming years. There will be enhancements in usability for it to continue being the easiest-to-use software in various fields. For instance, SmartPLS 4 will make importing data, creating models, managing projects, and analyzing results even more direct. In line with its fresh look and feel, rich graphical modeling capabilities are used to implement new methods and algorithms.

There are future plans to implement, for example, the generalized structured component analysis (GSCA) algorithm (Hwang et al., 2020; Hwang \& Takane, 2004), iterative reweighted segmentation (Schlittgen et al., 2016), Gaussian copulas (Hult et al., 2018; Park \& Gupta, 2012; Sarstedt et al., 2020b), and cross-validated predictive ability testing (CVPAT; Liengaard et al., 
2020). These are some examples of useful extensions to provide researchers and practitioners with an increasingly rich PLS-SEM analysis toolbox. Besides, the software can be extended to include additional statistical methods. For instance, simple regression models, including PROCESS-like analysis of mediation models (Hayes, 2018; Sarstedt et al., 2020a), exploratory and confirmatory factor analysis (Hair, et al., 2018a), and covariance-based structural equation modeling analogous to AMOS (Byrne, 2016) are being envisaged. Of course, these extensions will not come all at once.

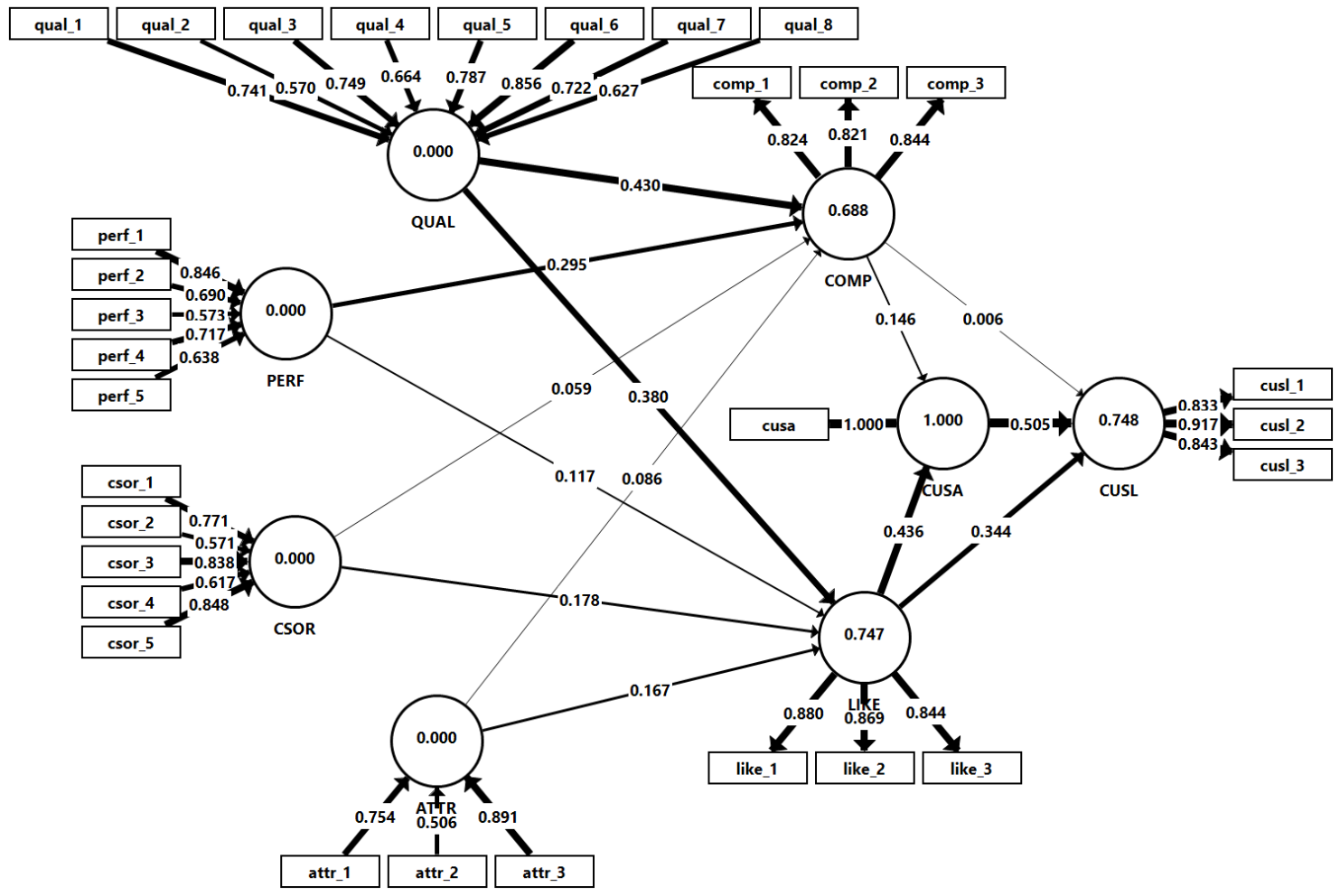

Figure 1: Corporate reputation model example and results in SmartPLS (Hair et al., 2022, 2018)

In a nutshell, SmartPLS will be progressively expanded in the coming years to facilitate various analyses. It can reasonably expect a bright future and will continue to establish itself as one of the leading standard statistical software solutions for research in academia and industry.

\section{WarpPLS}

Developed by Ned Kock single-handedly, WarpPLS is a software with a graphical user interface for variance-based and factor-based SEM using classic composite-based PLS and more modern factor-based methods. The software can be used in empirical research to analyze collected data (e.g., from surveys) and test hypothesized relationships. Since it runs on the MATLAB Compiler Runtime, it does not require the MATLAB software development application to be installed. In addition to Windows, it can be installed and used on various operating systems to allow virtualization practices. Among the main features of WarpPLS is its ability to identify and model non-linearity among variables in path models, whether these variables are measured as latent variables or not, thus yielding parameters that take corresponding underlying heterogeneity into consideration. 
A Google Scholar search reveals that more than 1,200 researchers have used WarpPLS in a variety of disciplines, including accounting, anthropology, clinical psychology, ecology, economics, education, global environmental change, epidemiology, evolutionary psychology, exercise physiology, information systems, international business, finance, management, marketing, medicine, nursing, organizational psychology, and sociology. Publications employing the software have also appeared in the most prestigious journals in their respective fields.

Like other PLS-SEM applications, WarpPLS has the ability to run a variety of analyses. WarpPLS is often used for basic PLS-SEM analysis (Kock, 2016b, 2017), factor-based SEM (Kock, 2019), moderation (Kock, 2020), mediation (Moqbel et al., 2020), non-linear relationships (Kock, 2016a), Simson's paradox (Kock \& Gaskins, 2016), modeling of dichotomous dependent variables, and latent growth analysis (Kock, 2020). One of the key elements that makes WarpPLS stand out is its ability to estimate full collinearity coefficients for assessing common method bias (Kock, 2015). Moreover, it can model both formative and reflective models, in addition to providing all important estimates, including confidence intervals, p-values, effect size, and predictive relevance. Besides, it calculates indirect and total effects for paths with several segments. The software further offers a number of cutting-edge features, such as causality assessment coefficients (see Figure 3), and zoomed 2D graphs and 3D graphs. A detailed user manual explaining the different functions and features of WarpPLS is available on its official website.

Although updates and improvements are made periodically without an apparent long-term direction and the software has yet to receive the widespread recognition and usage it deserves, WarpPLS continues to stay relevant to basic and applied research by introducing cutting edge features, such as the ability to address common method bias numerically and perform what-if analysis via simulations.

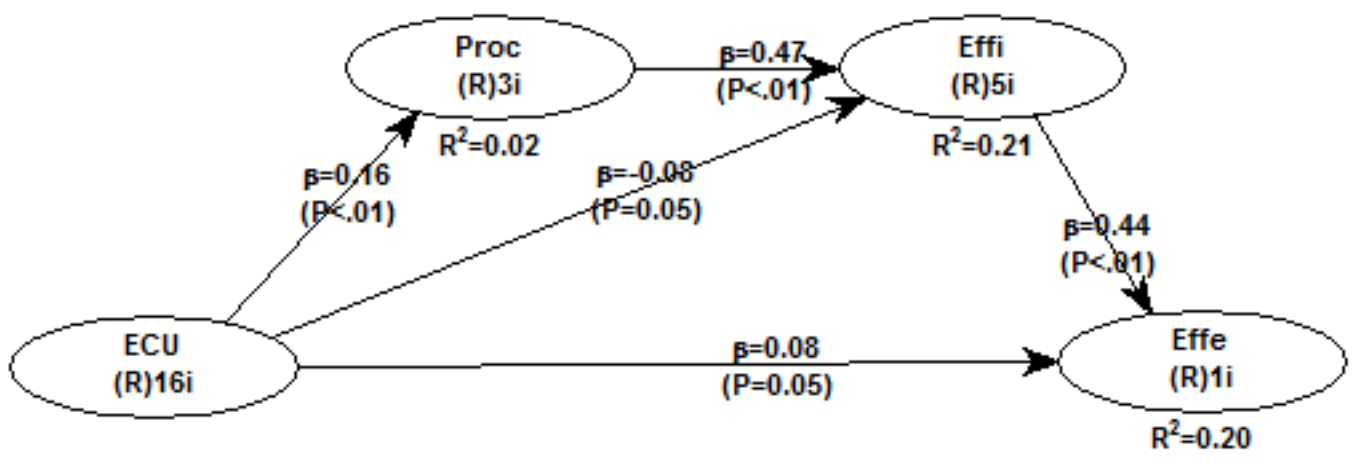

Figure 2: WarpPLS graphical user interface with model estimates

\section{ADANCO}

ADANCO, which stands for advanced analysis of composites, is another user-friendly software for composite-based SEM and confirmatory composite analysis. ADANCO was developed by Jörg Henseler and his team, and is distributed by Composite Modeling GmbH, a German company for statistical software (see Dijkstra \& Henseler, 2015a, 2015b; Henseler et al., 2014; Henseler et al., 2015; Henseler \& Schuberth, 2020; Schuberth et al., 2018). ADANCO is available for both Windows and Mac users. Along with its intuitive graphical user interface to specify structural equation models, it implements several limited-information estimators, such as PLS path modeling (Mode A, Mode A consistent, and Mode B) as well as an ordinary least squares 
regression based on sum scores. The current version is ADANCO 2.2.1, with ADANCO 2.3 expected to be released in spring 2021.

ADANCO has been designed with a focus on explanatory and confirmatory research to facilitate the analysis of causal relationships among constructs and the testing of theories (Henseler, 2018). It is also the PLS software of choice when a model's goodness-of-fit and consistency of parameter estimates are essential. To assess the fit of a structural equation model, ADANCO is able to perform bootstrap-based model fit tests (Bollen-Stine bootstrap). It clearly distinguishes between two types of constructs, latent variables and emergent variables, wherein latent variables are modeled as common factors. These variables are useful for capturing phenomena of behavioral research and are visualized as ovals in a structural equation model. Emergent variables, sometimes called "formative constructs", are modeled as composites and visualized as hexagons. They are useful for capturing management instruments and other human-made artifacts (Henseler, 2017). By default, ADANCO estimates the parameters of latent variables using consistent PLS and the parameters of emergent variables using traditional PLS. In that way, it ensures that users obtain consistent parameter estimates throughout the entire model. ADANCO makes use of the dominant-indicator approach (Henseler et al., 2016) to fix the orientation of constructs in order to secure the stability of parameter signs across bootstrap runs.

Core estimation results, such as path coefficients, loadings, weights, and coefficients of determination, are immediately visible in the modeling window. If a user requests the bootstrap, the significance of the estimates is also displayed. Besides, a well-structured report of the results is provided in HTML and MS Excel formats. The report is customizable, such that users can mix and match their optimal report from compact to comprehensive. The output covers all relevant results with regard to overall model fit, quality of the measurement model, coefficients of the structural model, and inferential statistics.

The newest feature of ADANCO is the confirmatory composite analysis, which concerns a model test of two or more correlated emergent variables, as depicted in Figure 2. Thus, ADONCO emphasizes its support in conducting a confirmatory composite analysis. Moreover, it is also possible to add latent variables to such a model so that users can conduct a combined confirmatory composite or factor analysis. There is ample literature support for ADANCO. Apart from freely available guideline papers, such as those by Benitez et al. (2020) and Henseler et al. (2016), there is Henseler's (2021) recently published textbook on composite-based SEM which contains tutorials on the use of the software. Moreover, ADANCO comes with a detailed user manual as well as a help system. Users of ADANCO have expressed their satisfaction with the clarity of the user interface and the software's ease of use. A quick scan of Google Scholar suggests that ADANCO has been discussed more than 100 times in the published literature since its first appearance in 2015, which indicates good reach in a relatively short time.

ADANCO is offered in several editions. The trial edition can help users to decide whether it would work for them in their research. The caveat of this edition is its functional limitation where only one latent variable can be estimated consistently while other latent variables are estimated using traditional PLS. Except the student edition, all other editions, including the academic edition for scholars and the professional edition for corporate use, come without any functional limitations. 


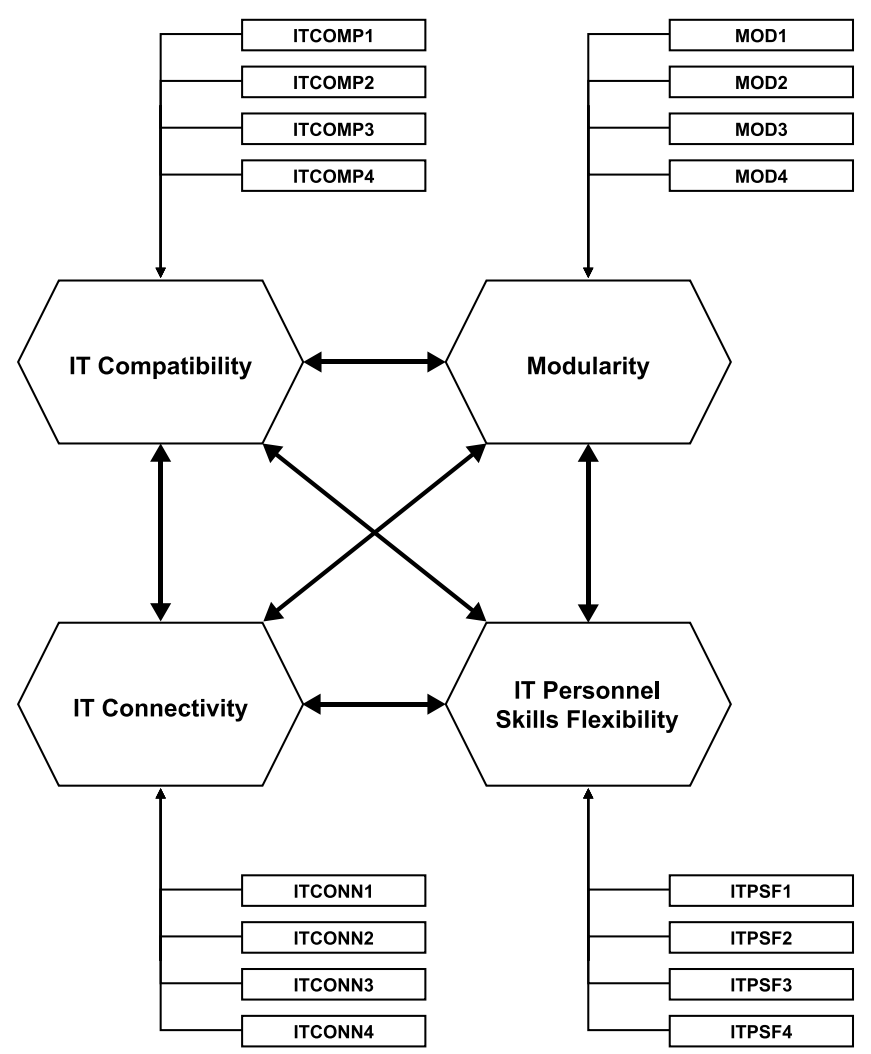

Figure 3: Confirmatory composite analysis of Benitez et al.'s (2018) study using ADANCO

(Henseler, 2021)

\section{A FINAL NOTE}

Despite the ongoing debate on the use and rigor of PLS-SEM, its methods continue to be prevalent in multivariate data analysis. We appreciate the efforts of predecessors in introducing and expanding the use of SEM, and we maintain our stance of embracing the advancement of statistical analysis by incumbent experts, be it in the form of affirmation or critique. Given growing social issues and the complexity of human behavior, there is no doubt that only software which is most adaptable to change, rather than that which is the fittest, will grow and be used perpetually. We are fully aware that what we employ today may be less useful or even obsolete after some time. Instead of being fixated on one method which has been useful in the past, it is prudent to keep ourselves abreast of the development of various methods over time. Beyond a mere clicking process, avid users, such as postgraduate students, should acquaint themselves with their research and its methodology to best utilize a software and its features.

Even though there are several PLS-SEM statistical analysis programs in the market, there is little difference between these programs in terms of their results when they are used appropriately with the right research design and procedures. While their features vary - for example, some applications are more established and offer a variety of analyses while some are relatively new and put an emphasis on certain types of analysis - all have a strong foundation in literature and have been consistently used in business and social science research. In no case does this editorial recommend the superiority of one application over another. Academics, professional users, and students who are undertaking their research should choose an application based on their research questions and design. We hope that this editorial serves as a starting point to understand the different characteristics of each application before making the appropriate choice. 


\section{ACKNOWLEDGEMENT}

We would like to thank the Prof. Christian M. Ringle (Hamburg University of Technology, Germany, and University of Waikato, New Zealand) and Prof. Dr. Jan-Michael Becker (BI Norwegian Business School, Norway), Prof. Ned Kock (Texas A\&M International University, USA), and Prof. Dr. Jörg Henseler (University of Twente, Netherlands) for their support and cooperation at the initial stages of this editorial.

\section{REFERENCES}

Aguirre-Urreta, M. I., \& Rönkkö, M. (2018), "Statistical Inference with PLSc Using Bootstrap Confidence Intervals", MIS Quarterly, 42(3), 1001-1020.

Becker, J.-M., \& Ismail, I. R. (2016), "Accounting for Sampling Weights in PLS Path Modeling: Simulatioetns and Empirical Examples", European Management Journal, 34(6), 606-617.

Becker, J.-M., Rai, A., Ringle, C. M., \& Völckner, F. (2013), "Discovering Unobserved Heterogeneity in Structural Equation Models to Avert Validity Threats", MIS Quarterly, 37(3), 665-694.

Becker, J.-M., Ringle, C. M., \& Sarstedt, M. (2018), "Estimating Moderating Effects in PLS-SEM and PLSc-SEM: Interaction Term Generation*Data Treatment", Journal of Applied Structural Equation Modeling, 2(2), 1-21.

Benitez, Jose; Ray, Gautam; Henseler, Jörg (2018), "Impact of Information Technology Infrastructure Flexibility on Mergers and Acquisitions", MIS Quarterly, 42 (1), 25-43.

Byrne, B. M. (2016). Structural Equation Modeling with AMOS: Basic Concepts, Applications, and Programming (Multivariate Applications) (3 ed.). New York: Routledge.

Cheah, J.-H., Roldán, J. L., Ciavolino, E., Ting, H., \& Ramayah, T. (2020a), "Sampling Weight Adjustments in Partial Least Squares Structural Equation Modeling: Guidelines and Illustrations", Total Quality Management \& Business Excellence, Vol. forthcoming.

Cheah, J.-H., Thurasamy, R., Memon, M. A., Chuah, F., \& Ting, H. (2020b), "Multigroup Analysis using SmartPLS: Step-by-Step Guidelines for Business Research", Asian Journal of Business Research, 10(3), 1-19.

Cheah, J. H., Ting, H., Ramayah, T., Memon, M. A., Cham, T. H., \& Ciavolino, E. (2019), "A Comparison of Five Reflective-Formative Estimation Approaches: Reconsideration and Recommendations for Tourism Research", Quality \& Quantity, 53(3), 142 1-1458.

Chin, W., Cheah, J. H., Liu, Y., Ting, H., Lim, X. J., \& Cham, T. H. (2020), "Demystifying the Role of Causal-Predictive Modeling Using Partial Least Squares Structural Equation Modeling in Information Systems Research", Industrial Management छ Data Systems, 120(12), 2161-2209.

Chin, W. W., \& Dibbern, J. (2010). A Permutation Based Procedure for Multi-Group PLS Analysis: Results of Tests of Differences on Simulated Data and a Cross Cultural Analysis of the Sourcing of Information System Services between Germany and the USA. In V. Esposito Vinzi, W. W. Chin, J. Henseler \& H. Wang (Eds.), Handbook of Partial Least Squares: Concepts, Methods and Applications (Springer Handbooks of Computational Statistics Series, vol. II) (pp. 171-193). Heidelberg, Dordrecht, London, New York: Springer.

Dijkstra, T. K. (2014), "PLS' Janus Face - Response to Professor Rigdon's 'Rethinking Partial Least Squares Modeling: In Praise of Simple Methods', Long Range Planning, 47(3), 146153.

Dijkstra, T. K., \& Henseler, J. (2015a), "Consistent and Asymptotically Normal PLS Estimators for Linear Structural Equations", Computational Statistics \& Data Analysis, 81(1), 10-23. 
Dijkstra, T. K., \& Henseler, J. (2015b), "Consistent Partial Least Squares Path Modeling", MIS Quarterly, 39(2), 297-316.

Gudergan, S. P., Ringle, C. M., Wende, S., \& Will, A. (2008), "Confirmatory Tetrad Analysis in PLS Path Modeling", Journal of Business Research, 61(12), 1238-1249.

Hahn, C., Johnson, M. D., Herrmann, A., \& Huber, F. (2002), "Capturing Customer Heterogeneity Using a Finite Mixture PLS Approach", Schmalenbach Business Review, 54(3), 243-269.

Hair, J. F. (2020), "Next Generation Prediction Metrics for Composite-based PLS-SEM. Industrial Management \& Data Systems", 121(1), 5-11.

Hair, J. F., Black, W. C., Babin, B. J., \& Anderson, R. E. (2018a). Multivariate Data Analysis (8 ed.). Mason, $\mathrm{OH}$ : Cengage.

Hair, J. F., Howard, M. C., and Nitzl, C. (2020), "Assessing Measurement Model Quality in PLSSEM Using Confirmatory Composite Analysis", Journal of Business Research, 109, 101110.

Hair Jr, J. F., \& Sarstedt, M. (2019), "Factors versus composites: guidelines for choosing the right structural equation modeling method", Project Management Journal, 50(6), 619-624.

Hair, J. F., Risher, J. J., Sarstedt, M., \& Ringle, C. M. (2019a), "When to Use and How to Report the Results of PLS-SEM", European Business Review, 31(1), 2-24.

Hair, J. F., Sarstedt, M., \& Ringle, C. M. (2019b), "Rethinking Some of the Rethinking of Partial Least Squares. European Journal of Marketing", 53(4), 566-584.

Hair, J. F., Hult, G. T. M., Ringle, C. M., \& Sarstedt, M. (2022). A Primer on Partial Least Squares Structural Equation Modeling (PLS-SEM) (3 ed.). Thousand Oaks, CA: Sage. forthecoming.

Hair, J. F., Sarstedt, M., Ringle, C. M., \& Gudergan, S. P. (2018b). Advanced Issues in Partial Least Squares Structural Equation Modeling (PLS-SEM). Thousand Oaks, CA: Sage.

Hayes, A. F. (2018). Introduction to Mediation, Moderation, and Conditional Process Analysis: A Regression-Based Approach (2 ed.). New York, NY: The Guilford Press.

Henseler, J., \& Dijkstra, T. K. (2015). ADANCO. GmbH \& Co. Kleve. Germany. Retrieved from http://www. compositemodeling.com.

Henseler, J., Ringle, C. M., \& Sarstedt, M. (2015), "A New Criterion for Assessing Discriminant Validity in Variance-based Structural Equation Modeling", Journal of the Academy of Marketing Science, 43(1), 115-135.

Henseler, J., Ringle, C. M., \& Sarstedt, M. (2016), "Testing Measurement Invariance of Composites Using Partial Least Squares", International Marketing Review, 33(3), 405-431.

Henseler, J. (2021). Composite-Based Structural Equation Modeling: Analyzing Latent and Emergent Variables, New York: Guilford Press.

Henseler, J. (2018), "Partial Least Squares Path Modeling: Quo Vadis?", Quality \& Quantity, 52 (1), 1-8.

Henseler, J. (2017), "Bridging Design and Behavioral Research with Variance-Based Structural Equation Modeling", Journal of Advertising, 46 (1), 178-192.

Henseler, J.; Dijkstra, T. K.; Sarstedt, M.; Ringle, C. M.; Diamantopoulos, A.; Straub, D. W.; Ketchen, D. J., Hair, J. F.; Hult, G. T. M.; Calantone, R. J. (2014), "Common Beliefs and Reality About PLS: Comments on Rönkkö \& Evermann (2013)", Organizational Research Methods, 17 (2), 182-209.

Henseler, J.; Hubona, G.; Ray, A. A. (2016), "Using PLS Path Modeling in New Technology Research: Updated Guidelines", Industrial Management \& Data Systems, 116 (1), 2-20. 
Henseler, J.; Ringle, C. M.; Sarstedt, M. (2015), "A New Criterion for Assessing Discriminant Validity in Variance-Based Structural Equation Modeling", Journal of the Academy of Marketing Science, 43 (1), 115-135.

Henseler, J. \& Schuberth, F. (2020), "Using Confirmatory Composite Analysis to Assess Emergent Variables in Business Research", Journal of Business Research, 120 (November), $147-156$.

Hult, G. T. M., Hair, J. F., Proksch, D., Sarstedt, M., Pinkwart, A., \& Ringle, C. M. (2018), "Addressing Endogeneity in International Marketing Applications of Partial Least Squares Structural Equation Modeling", Journal of International Marketing, 26(3), pp. 121.

Hwang, H., Sarstedt, M., Cheah, J. H., \& Ringle, C. M. (2020), "A Concept Analysis of Methodological Research on Composite-based Structural Equation Modeling: Bridging PLSPM and GSCA", Behaviormetrika, 47. 219-241.

Hwang, H., \& Takane, Y. (2004), "Generalized Structured Component Analysis", Psychometrika, 69(1), 81-99.

Kock, N. (2015), "Common Method Bias in PLS-SEM: A Full Collinearity Assessment Approach", International Journal of e-Collaboration, 11(4), 1-10.

Kock, N. (2016a), "Advantages of Nonlinear Over Segmentation Analyses in Path Models", International Journal of e-Collaboration, 12(4), 1-6.

Kock, N. (2016b), "Hypothesis Testing With Confidence Intervals and P Values in PLS-SEM", International Journal of e-Collaboration, 12(3), 1-6.

Kock, N. (2017). WarpPLS 6.o User Manual. Retrieved from http://warppls.com/

Kock, N. (2019), "Factor-Based Structural Equation Modeling with WarpPLS", Australasian Marketing Journal, 27(1), 57-63.

Kock, N. (2020), "Full latent growth and its use in PLS-SEM: Testing moderating relationships", Data Analysis Perspectives Journal, 1(1), 1-5.

Kock, N., \& Gaskins, L. (2016), "Simpson's paradox, moderation and the emergence of quadratic relationships in path models: an information systems illustration", International Journal of Applied Nonlinear Science, 2(3), 200-234.

Kock, N., \& Hadaya, P. (2018), "Minimum Sample Size Estimation In PLS-SEM: The Inverse Square Root and Gamma-Exponential Methods", Information Systems Journal, 28(1), 227261.

Liengaard, B., Sharma, P. N., Hult, G. T. M., Jensen, M. B., Sarstedt, M., Hair, J. F., \& Ringle, C. M. (2021), "Prediction: Coveted, Yet Forsaken? Introducing a Cross-validated Predictive Ability Test in Partial Least Squares Path Modeling", Decision Sciences, 52(2), 362-392.

Lohmöller, J.-B. (1989). Latent Variable Path Modeling with Partial Least Squares. Heidelberg: Physica.

Marcoulides, G. A., Chin, W. W., \& Saunders, C. (2012), "When Imprecise Statistical Statements Become Problematic: A Response to Goodhue, Lewis, and Thompson", MIS Quarterly, 36(3). 717-728.

Memon, M. A., Ting, H., Ramayah, T., Chuah, F., \& Cheah, J.-H. (2017), "A review of the methodological misconceptions and guidelines related to the application of structural equation modeling: A Malaysian scenario", Journal of Applied Structural Equation Modeling, 1(1), i-xiii.

Memon, M. A., Cheah, J.-H., Ramayah, T., Ting, H., \& Chuah, F. (2018), "Mediation Analysis: Issues and Recommendations", Journal of Applied Structural Equation Modeling, 2(1), i-ix. 
Memon, M. A., Cheah, J.-H., Ramayah, T., Ting, H., Chuah, F., \& Cham, T. H. (2019), "Moderation Analysis: Issues and Guidelines", Journal of Applied Structural Equation Modeling, 3(1), i-xi.

Memon, M. A., Ting, H., Cheah, J.-H., Ramayah, T., Chuah, F., \& Cham, T. H. (2020), "Sample size for survey research: review and recommendations", Journal of Applied Structural Equation Modelling, 4(2), i-xx.

Moqbel, M., Guduru, R., \& Harun, A. (2020), "Testing Mediation Via Indirect Effects in PLSSEM: A social networking site illustration", Data Analysis Perspectives Journal, 1(3), 1-6.

Nitzl, C., Roldán, J. L., \& Cepeda Carrión, G. (2016), "Mediation Analysis in Partial Least Squares Path Modeling: Helping Researchers Discuss More Sophisticated Models", Industrial Management Eं Data Systems, 119(9), 1849-1864.

Park, S., \& Gupta, S. (2012), "Handling Endogenous Regressors by Joint Estimation Using Copulas", Marketing Science, 31(4), 567-586.

Ramayah, T., Jun-Hwa, C., Chuah, F., Ting, H., \& Memon, M. A. (2018). Partial Least Squares Structural Equation Modeling (PLS-SEM) using SmartPLS 3.0: An Updated Guide and Practical Guide to Statistical Analysis (2nd ed.). Kuala Lumpur, Malaysia: Pearson.

Rigdon, E. E., Sarstedt, M., \& Ringle, C. M. (2017), "On Comparing Results From CB-SEM and PLS-SEM: Five Perspectives And Five Recommendations", Marketing: ZFP-Journal of Research and Management, 39(3), 4-16.

Ringle, C. M., \& Sarstedt, M. (2016), "Gain More Insight from Your PLS-SEM Results: The Importance-Performance Map Analysis", Industrial Management \& Data Systems, 116(9), 1865-1886.

Ringle, C. M., Wende, S., \& Becker, J. M. (2015). SmartPLS 3. SmartPLS GmbH. Boenningstedt. Retrieved from http://www.smartpls.com

Russo, D., \& Stol, K.-J. (202 1), "PLS-SEM for Software Engineering Research: An Introduction and Survey", ACM Computing Surveys, 1(1), 1-19.

Sarstedt, M., Becker, J.-M., Ringle, C. M., \& Schwaiger, M. (2011), "Uncovering and Treating Unobserved Heterogeneity with FIMIX-PLS: Which Model Selection Criterion Provides an Appropriate Number of Segments?", Schmalenbach Business Review, 63(1), 3462.

Sarstedt, M., \& Cheah, J. H. (2019), "Partial Least Squares Structural Equation Modeling Using SmartPLS: A Software Review", Journal of Marketing Analytics, 7, 196-202.

Sarstedt, M., Hair, J. F., Cheah, J.-H., Becker, J.-M., \& Ringle, C. M. (2019), "How to Specify, Estimate, and Validate Higher-order Constructs in PLS-SEM", Australasian Marketing Journal, 27(3), 197-211.

Sarstedt, M., Hair, J. F., Nitzl, C., Ringle, C. M., \& Howard, M. C. (2020a), "Beyond a Tandem Analysis of SEM and PROCESS: Use of PLS-SEM for Mediation Analyses!", International Journal of Market Research, 62(3), 288-299.

Sarstedt, M., Hair, J. F., Ringle, C. M., Thiele, K. O., \& Gudergan, S. P. (2016), "Estimation issues with PLS and CBSEM: Where the bias lies!", Journal of Business Research, 69(10).

Sarstedt, M., Ringle, C. M., Cheah, J. H., Ting, H., Moisescu, O. I., \& Radomir, L. (2020b), "Structural Model Robustness Checks in PLS-SEM", Tourism Economics, 26(4), 531-554.

Schlittgen, R., Ringle, C. M., Sarstedt, M., \& Becker, J.-M. (2016), "Segmentation of PLS Path Models by Iterative Reweighted Regressions", Journal of Business Research, 69(10), 45834592 .

Schuberth, F., Rademaker, M. E., \& Henseler, J. (2020), "Estimating and Assessing Second-Order Constructs Using PLS-PM: The Case of Composites Of Composites", Industrial Management \& Data Systems, 120(12), 221 1-2241. 
Schuberth, F.; Henseler, J.; Dijkstra, T. K. (2018), "Confirmatory Composite Analysis", Frontiers in Psychology, 9, Article 2541. 1-14

Sharma, P. N., Sarstedt, M., Shmueli, G., Kim, K. H., \& Thiele, K. O. (2019a), "PLS-Based Model Selection: The Role of Alternative Explanations in Information Systems Research", Journal of the Association for Information Systems, 20(4), 346-397

Sharma, P. N., Shmueli, G., Sarstedt, M., Danks, N., \& Ray, S. (2019b), "Prediction-oriented model selection in partial least squares path modeling", Decision Sciences, Forthcoming. DOI: https://doi.org/10.1111/deci.12329

Shmueli, G., Ray, S., Velasquez Estrada, J. M., \& Chatla, S. B. (2016), "The Elephant in the Room: Evaluating the Predictive Performance of PLS Models", Journal of Business Research, 69(10), 4552-4564.

Shmueli, G., Sarstedt, M., Hair, J. F., Cheah, J., Ting, H., Vaithilingam, S., \& Ringle, C. M. (2019), "Predictive Model Assessment in PLS-SEM: Guidelines for Using PLSpredict", European Journal of Marketing, 53(11), 2322-2347.

Van Riel, A. C., Henseler, J., Kemény, I., \& Sasovova, Z. (2017), "Estimating Hierarchical Constructs Using Consistent Partial Least Squares: The Case of Second-Order Composites of Common Factors", Industrial Management \& Data Systems, 117 (3), 459477 .

Wetzels, M., Odekerken-Schroder, G., \& van Oppen, C. (2009), "Using PLS Path Modeling for Assessing Hierarchical Construct Models: Guidelines and Empirical Illustration", MIS Quarterly, 33(1), 177-195.

Wold, H. (1982). Soft Modeling: The Basic Design and Some Extensions. In K. G. Jöreskog \& H. O. A. Wold (Eds.), Systems Under Indirect Observations: Part II (pp. 1-54). Amsterdam: North-Holland. 